\title{
Ambivalent sexism and perceptions of men and women who violate gendered family roles
}

\author{
Ruth Gaunt* \\ Department of Sociology, University of Cambridge, Cambridgeshire, UK
}

(Received 6 June 2012; final version received 14 November 2012)

This study draws on ambivalent sexism theory to explore the role of benevolent
and hostile gender attitudes in determining perceptions of individuals who
comply with traditional gender roles or violate them. Three hundred and eleven
participants were presented with a description of a male or a female target who
was either a primary breadwinner or a primary caregiver. As hypothesized, hostile
sexism (HS) predicted more negative perceptions of a female breadwinner,
whereas benevolent sexism (BS) predicted more positive perceptions of a female
caregiver. Moreover, participants who endorsed hostile attitudes toward men
reacted more positively to a nontraditional male caregiver, whereas those who
endorsed benevolent attitudes toward men reacted more negatively to a male
caregiver. Implications regarding the nature of ambivalent gender attitudes are
discussed.

Keywords: ambivalent sexism; ambivalence toward men; family roles; gender norms

Cette étude s'appuie sur la théorie du sexisme ambivalent à explorer le rôle des attitudes sexistes bienveillants et hostile à déterminer les perceptions des individus qui se conforment aux rôles traditionnels des sexes ou les violer. Trois cent onze participants ont été présentés avec une description d'un mâle ou d'une cible féminine qui était soit un principal soutien de famille ou un soignant primaire. Comme hypothèse, le sexisme hostile prédit des perceptions plus négatives du soutien de famille femelle, tandis que sexisme bienveillant prédit une perception plus positive de femme au foyer. De plus, les participants qui ont approuvé les attitudes hostiles envers les hommes ont réagi plus positivement à un fournisseur de soins non traditionnels de sexe masculin, alors que ceux qui ont approuvé l'attitude bienveillante envers les hommes ont réagi plus négativement à un soignant de sexe masculin. Implications quant à la nature des attitudes ambivalentes entre les sexes sont discutées.

Mots-clés: sexisme ambivalent; ambivalence envers les homes; les rôles familiaux; les normes de genre

\section{Introduction}

Women's roles in Western societies have changed dramatically in the last several decades. Increasing proportions of women work for pay outside the home, including mothers of young children (Scott, Dex, \& Joshi, 2008). These changes have not been paralleled by an equivalent change in men's roles in the familial sphere, and women

*Email: rg433@cam.ac.uk 


\section{R. Gaunt}

continue to perform the vast majority of housework and childcare (Knudsen \& Waerness, 2008). Ample research has been conducted in an attempt to account for the persistence of gender inequality in the home (see for a review Lachance-Grzela \& Bouchard, 2010), which in turn also contributes to the gender pay gap (Gershuny, 2004). Many researchers have drawn attention to the important role played by gender attitudes and ideologies in inhibiting or facilitating changes in the division of labor (e.g., Bulanda, 2004; Gaunt, 2006; Greenstein, 1996), some of them specifically addressing people's perceptions of men and women who violate traditional family roles (e.g., Bridges, Etaugh, \& Barnes-Farrell, 2002; Park, Smith, \& Correll, 2008).

The present study attempts to understand perceptions of gender norm violators within the framework of ambivalent sexism theory (Glick \& Fiske, 1996, 1999, 2001). Specifically, it tests the hypotheses derived from ambivalent sexism theory concerning the role of benevolent and HS in determining perceptions of women who comply with traditional family roles and those who contest those roles. It extends previous studies on ambivalent sexism by addressing the relatively neglected issue of ambivalent attitudes toward men. Specifically, it focuses on the ways in which benevolent and hostile attitudes toward men shape people's perceptions of men who conform to their normative roles as breadwinners and those who violate them. Moreover, whereas previous studies on sexism have used abstract category labels that are stereotypic in nature (e.g., 'homemakers,' 'career women'), this study extends the extant literature by showing the effects of ambivalent sexism on judgments of individualized targets. To this end, it uses hypothetical scenarios describing the daily life of an individual varying systematically in terms of gender and role.

\section{Perceptions of deviations from gendered family roles}

Although social judgments and evaluations play an important role in facilitating or inhibiting the pursuit of greater gender equality, relatively few studies have explored people's perceptions of men and women who violate traditional family roles (e.g., Bridges et al., 2002; Part et al., 2008). These studies have mainly focused on the valence of people's responses, comparing participants' perceptions of individuals who conform to traditional gender roles and their perceptions of those who challenge these roles.

Most of the studies along this line have reported negative judgments of gender role violators. For example, in Etaugh and Folger's study (1998), a woman who continued to work full-time after the birth of a child was rated as less nurturant than a similarly described man, and a man who reduced his work hours after the birth of a child was rated as less competent than a similarly described woman. In a similar manner, Brescoll and Uhlmann (2005) found that participants felt less warmly toward an employed mother and a stay-at-home father than their traditional counterparts, believed that the stay-at-home father was a worse parent, and viewed the employed mother as more selfish than the employed father. More recently, Coleman and Franiuk (2011) found that a woman who returned to work immediately after the birth of a child was viewed as less warm than a woman who took a temporary leave or stayed at home, while a man who stayed at home was viewed as less competent than a man who took a temporary leave or remained working (Coleman \& Franiuk, 2011). 
Whereas all of these studies have manipulated target gender, parental and employment roles, none has explored how the perceptions of those who violate gender norms vary as a function of the participants' own social-psychological characteristics. That is, the effect of participants' pre-existing gender attitudes and ideologies has not been examined to date. To help fill this gap, the present study seeks to examine whether participants' ambivalent attitudes toward men and women determine their views of individual targets who challenge restrictive gender roles.

\section{Ambivalent sexism theory}

Ambivalent sexism theory (Glick \& Fiske, 1996, 1999, 2001) posits that the relations between the genders are characterized by the coexistence of power differences and strong interdependence. Traditional attitudes toward men and women therefore encompass considerable ambivalence, consisting of both hostile and benevolent components (Glick \& Fiske, 1996, 2001).

The Ambivalent Sexism Inventory (ASI; Glick \& Fiske, 1996, 1997) was developed to measure hostile and benevolent attitudes toward women. Hostile sexism (HS) expresses antipathy and resentment toward women who are perceived as violating traditional roles or challenging male dominance (e.g., 'most women fail to appreciate fully all that men do for them,' 'women seek to gain power by getting control over men'). In contrast, benevolent sexism (BS) is a subjectively positive and affectionate attitude, portraying women as weak beings who ought to be protected and provided for by men (e.g., 'many women have a quality of purity that few men possess,' 'women should be cherished and protected by men'). Ambivalent sexism theory suggests that hostility and benevolence toward women form a complementary belief system that reinforces gender inequality. Benevolence is expressed toward women who conform to traditional roles, whereas hostility is directed toward women who violate those roles (Glick et al., 2000).

Similarly, the Ambivalence Toward Men Inventory (AMI; Glick \& Fiske, 1999) was designed to measure hostile and benevolent attitudes toward men. Hostility toward men (HM) expresses resentment of men's power and aggressiveness (e.g., 'men usually try to dominate conversations when talking to women,' 'a man who is sexually attracted to a woman typically has no morals about doing whatever it takes to get her in bed'). Although reflecting antagonism to men's higher status, these hostile attitudes characterize men as inherently powerful and aggressive, thus portraying male dominance as natural and inevitable (Glick et al., 2004). In contrast, benevolence toward men (BM) acknowledges and admires men's traditional roles of protectors and providers (e.g., 'men are more willing to put themselves in danger to protect others,' 'every woman ought to have a man she adores'). Together, hostility and BM are complementary traditional beliefs, with HM characterizing men as powerful and arrogant and BM admiring their traditional gender roles.

Cross-cultural studies have shown that hostile and benevolent attitudes toward women are positively correlated with each other (Glick et al., 2000, 2004) as are hostile and benevolent attitudes toward men (Glick et al., 2004). All four sub-scales were found to be negatively correlated with indicators of gender equality across 16 nations (Glick et al., 2004).

Several studies have further indicated that ambivalent sexism is related to personal preferences and attitudes toward various features of gender relationships. 


\section{$4 \quad$ R. Gaunt}

For example, HS was positively related to the endorsement of restrictive beauty standards (Forbes, Adams-Curtis, Hamm, \& White, 2007) and to attitudes toward violence against wives (Glick, Sakalli-Ugurlu, Ferreira, \& De Souza, 2002). Benevolent and HS were positively related to attitudes toward women who breastfeed (Forbes, Collinsworth, Jobe, Braun, \& Wise, 2003), and predicted relationship ideals and preferences for romantic partners across culturally diverse samples (Chen, Fiske, \& Lee, 2009; Eastwick et al., 2006; Lee, Fiske, Glick, \& Chen, 2010; Travaglia, Overall, \& Sibley, 2009). The current study aims to explore the role of ambivalent gender attitudes in shaping people's views of deviations from prescriptive gender roles.

\section{Ambivalent sexism and gender norm violators}

Surprisingly few studies have been conducted that specifically address the relationships between sexist beliefs and perceptions of deviations from traditional gender roles. According to the ambivalent sexism theory, HS is directed toward women who threaten male dominance, whereas BS is directed toward women who comply with restrictive female roles (Glick \& Fiske, 1996). In line with these predictions, Glick, Diebold, Bailey-Werner, and Zhu (1997) found that men's HS uniquely predicted negative attitudes toward career women, whereas men's BS uniquely predicted positive attitudes toward homemakers. Complementary evidence for this differential role of hostile and BS comes from a more recent study with female participants (Becker, 2010). In this study, the more women thought about career women while completing the HS scale, the greater was their endorsement of hostile sexist beliefs. In contrast, the more women thought about housewives while completing the BS scale, the greater was their endorsement of benevolent sexist beliefs (Becker, 2010).

The current study similarly explores attitudes toward individuals who fail to comply with traditional family roles. It extends previous studies in two important ways. First, previous studies on sexism and judgments of traditional and nontraditional roles have typically asked participants to respond to abstract category labels (e.g., 'homemakers,' 'career women'). This procedure may elicit more stereotypical images and responses because stereotypes have stronger effects on judgments directed at groups than on judgments directed at individuals (Gill, 2003). In order to avoid the stereotypic nature of such simple categorical descriptions, the present study asked participants to respond to scenarios describing the daily life of an individual man or woman.

Second, and more importantly, studies of ambivalent gender attitudes typically deal with the associations between ambivalent sexism and attitudes toward female roles (Becker, 2010; Glick et al., 1997) or female characteristics and behaviors (Abrams, Viki, Masser, \& Bohner, 2003; Forbes et al., 2003, 2007; Fowers \& Fowers, 2010). Little is known, however, about the implications of ambivalence toward men and how hostile and benevolent attitudes shape people's views of men in various roles. An exception is Sakalli-Ugurlu's study (2010) in which she examined attitudes toward men in the domain of academic studies. In this study, HS predicted negative attitudes toward women studying natural sciences, while BM predicted negative attitudes toward men studying social sciences (Sakalli-Ugurlu, 2010). To broaden our understanding of the implications of ambivalent attitudes toward men, the current study investigates the role of these attitudes in determining perceptions of 
men in a traditional and nontraditional role, in addition to investigating the effects of sexism on perceptions of women.

\section{Overview and hypotheses}

The goal of the current study was to assess the effects of ambivalent sexism and ambivalent attitudes toward men on people's perceptions of men and women who conform to traditional family roles or violate them. For this purpose, participants were presented with a description of a male or a female target who is a primary breadwinner married to a primary caregiver or vice versa.

Ambivalent sexism theory provides well-formulated predictions regarding the differential relationships between hostile and benevolent sexist attitudes and perceptions of traditional and nontraditional women. The theory suggests that HS exclusively predicts negative attitudes toward women who challenge traditional gender norms (e.g., career women), and BS exclusively predicts positive attitudes toward women who fulfill a traditional female role (e.g., homemakers; Glick \& Fiske, 1996, 2001). In line with these predictions and with previous findings with abstract category labels (Glick et al., 1997), it was hypothesized that:

(1) HS would be related to negative perceptions of a female breadwinner;

(2) BS would be related to positive perceptions of a female caregiver.

The predictions derived from ambivalent sexism theory regarding perceptions of men in various roles are less straightforward. According to the theory, both hostile and benevolent attitudes reflect responses to the traditional, powerful male provider (Glick \& Fiske, 1999). Hostile attitudes toward men should therefore predict negative judgments of a male breadwinner, while benevolent attitudes toward men should predict positive judgments of a male breadwinner. The opposite pattern of results should be expected for a male caregiver. If benevolent attitudes toward men express admiration to the male provider role, they should predict negative perceptions of a man who does not comply with this role. Similarly, given that hostile attitudes toward men express resentment of male power and aggressiveness, such attitudes should predict positive perceptions of a man who gave up his dominant role as a primary breadwinner and serves as a primary caregiver instead. It was therefore hypothesized that:

(1) HM would be related to negative perceptions of a male breadwinner and positive perceptions of a male caregiver;

(2) BM would be related to positive perceptions of a male breadwinner and negative perceptions of a male caregiver.

To test these predictions, participants' ambivalent gender attitudes were measured as well as their perceptions of a target in a hypothetical scenario. Participants read about a target person who varied systematically in terms of gender and role: a male or a female target was described as a full-time employee married to a part-time employee who is the primary caregiver, or as a part-time employee who is the primary caregiver and is married to a full-time employee. Participants' perceptions were measured in terms of their attributions of traits and emotions to the target. 


\section{$6 \quad$ R. Gaunt}

Drawing on Fiske and colleagues' theorization regarding the fundamental nature of warmth and competence dimensions of social judgment (Cuddy, Fiske, \& Glick, 2008; Fiske, Cuddy, \& Glick, 2007), participants attributions of warmth and competence related traits were measured, as well as attributions of positive and negative emotions to the target.

The study was conducted on a sample of Jewish Israeli adults. In Israel, as in other Western-oriented countries, there has been a massive entry of women into the labor force over the last few decades (Lavee \& Katz, 2003). As a result, the dualearner family pattern has become the most frequent one, and the rates of Jewish Israeli mothers in the labor force range from $84 \%$ (for mothers of 2-4-year-old children) to $86 \%$ (for mothers of 5 to 9-year-old children; Central Bureau of Statistics, 2009). In a cross-cultural comparison of attitudes toward maternal employment, only $10 \%$ of Israeli women (compared to an average of $45 \%$ in several English-speaking countries) agreed that mothers should not be employed when they have a pre-schoolchild (Charles \& Cech, 2010). In spite of these liberal views and high employment rates, Israeli women continue to bear primary responsibility for housework and childcare (Lavee \& Katz, 2003) to a similar extent as women in other Western countries (Knudsen \& Waerness, 2008).

\section{Method}

\section{Participants and procedure}

Participants were 311 adults (154 men and 157 women) recruited by research assistants as part of a larger research project. They were personally approached by the assistants in public areas such as cafes, work places, and university campuses in five towns in Israel. The study was introduced to participants as investigating the process of forming impression of others. Participants were not compensated and all responses were anonymous. Data from additional five respondents were discarded because important demographic information was missing. The participants' ages ranged from 18 to 57 years $(M=28.31, \mathrm{SD}=6.06)$, with $78 \%$ of the participants between 24 and 30 years of age. Of the participants, $13 \%$ had a high school diploma, $25 \%$ had some college education or technical training, and $62 \%$ had a university degree. The majority of the participants were unmarried, $24 \%$ were married, and $14 \%$ had children.

Participants were randomly assigned to one of four conditions. Seventy-six participants (38 men and 38 women) read about a female breadwinner, 74 (34 men and 40 women) read about a female caregiver, 76 ( 40 men and 36 women) read about a male breadwinner, and 85 ( 42 men and 43 women) read about a male caregiver.

\section{Measures}

Ambivalent sexism

Participants' attitudes toward women were measured using the 22-item ASI (Glick \& Fiske, 1996). The 22 items were translated into Hebrew and back-translated as in previous cross-cultural studies with the ASI (Glick et al., 2000, 2004). Following Glick et al.'s recommendation (Glick et al., 2000), nonreversed wording was used for all items in the translated version. Participants responded to the items by using a 
six-point scale labeled disagree strongly (0), disagree somewhat (1), disagree slightly (2), agree slightly (3), agree somewhat (4), and agree strongly (5). The ASI consisted of two sub-scales: HS which assesses sexist antipathy toward women, and BS which assesses subjectively positive but patronizing attitudes toward women. The average score for each sub-scale was computed to obtain the respondent's HS and BS scores. A high score reflected more hostile or benevolent attitudes. Cronbach's alphas for these measures were 0.91 and 0.87 , respectively.

\section{Ambivalent attitudes toward men}

Participants' attitudes toward men were measured using the 20-item AMI (Glick \& Fiske, 1999). The 20 items were translated into Hebrew and back-translated as in previous cross-cultural studies with the AMI (Glick et al., 2004). Non-reversed wording was used for all items in the translated version (as recommended by Glick et al., 2000). Participants responded to the items by using a six-point scale labeled disagree strongly (0), disagree somewhat (1), disagree slightly (2), agree slightly (3), agree somewhat (4), and agree strongly (5). The AMI consisted of two subscales: HM which assesses resentment toward male dominance, and $\mathrm{BM}$ which assesses appreciation toward men as providers and protectors. The average score for each sub-scale was computed to obtain the respondent's HM and BM scores. A high score reflected more hostile and benevolent attitudes toward men. Cronbach's alphas for these measures were 0.86 and 0.89 , respectively.

\section{Target manipulation}

Participants in the primary caregiving target condition read the following:

Dan (Dina) is 34 years old, married, and a parent to Adam (age 5) and Mika (age 2). Dan (Dina) is at work until 1:00 pm, and then picks up the children from kindergarten and takes care of the housework and childcare (cooking, feeding the children, giving them a bath, doing the laundry, driving the children to social and other activities etc.). His wife (Her husband) is a successful manager in a big firm. She (He) leaves home early in the morning, and usually returns between 7 and $8 \mathrm{pm}$.

Participants in the breadwinning target condition read the following:

Dina (Dan) is 34 years old, married, and a parent to Adam (age 5) and Mika (age 2). She $(\mathrm{He})$ is a successful manager in a big firm. She $(\mathrm{He})$ leaves home early in the morning, and usually returns between 7 and $8 \mathrm{pm}$. Her husband (His wife) is at work until 1:00 pm, and then picks up the children from kindergarten and takes care of the housework and childcare (cooking, feeding the children, giving them a bath, doing the laundry, driving the children to social and other activities etc.).

\section{Manipulation checks}

To assess whether work and family roles were successfully manipulated, participants were asked to estimate the target's and spouse's number of work hours per week. Participants also rated the earnings of the target relative to those of the spouse on a five-point Likert scale ranging from Dan (Dina) earns much more (1) through their earnings are approximately equal (3) to His wife (Her husband) earns much more (5). 


\section{R. Gaunt}

\section{Attribution of warmth and competence}

Fiske and her colleagues (Cuddy, Fiske, \& Glick, 2008; Fiske et al., 2007) suggested that warmth and competence are enduring fundamental dimensions of social judgments. Participants' perceptions of the target's warmth and competence were therefore assessed, using a 12-item measure consisting of six competence-related traits (e.g., intelligent, hard-working) and six warmth-related traits (e.g., nice, selfish; Fiske, Cuddy, Glick, \& Xu, 2002). Half of the traits in each category were positive and half were negative. Participants rated the extent to which they thought that the target person was characterized by each of the 12 traits on five-point Likert-type scales anchored by not at all (1) and very much (5). Responses were recoded so that a high score reflected more positive trait attribution. The average scores for the six warmth-related traits and six competence-related traits were computed to obtain the respondent's warmth and competence attribution scores. Internal reliabilities (Cronbach's alphas) for these measures were 0.84 and 0.69 , respectively.

\section{Attribution of positive and negative emotions}

Participants' attributions of emotions to the target person were assessed using a sixitem measure consisting of three positive emotions (happiness, satisfaction, and selffulfillment) and three negative emotions (sadness, frustration, and guilty conscience). Participants rated the extent to which they thought that the target person experienced each of the six emotions on five-point Likert-type scales anchored by not at all (1) and very much (5). The average scores for the three positive emotions and three negative emotions were computed to obtain the respondent's attributions of positive and negative emotions. Internal reliabilities (Cronbach's alphas) for these measure were 0.68 and 0.74 , respectively.

\section{Demographic variables}

Participants reported their sex, age, level of education, family status, and level of religiosity.

\section{Results}

\section{Role manipulation check}

The analysis of the manipulation check variables confirmed that the participants correctly comprehended the division of roles. Participants estimated the breadwinning target's number of work hours $(M=57.77)$ as significantly greater than the caregiving target's number of work hours $(M=26.58), t(309)=53.57, p<0.001$. In addition, participants rated the breadwinning target's relative earnings $(M=4.94)$ as significantly higher than the caregiving target's relative earnings $(M=1.07)$, $t(309)=138.89, p<0.001$.

\section{Gender differences in ambivalent attitudes toward men and women}

Means, standard deviations and $t$-test comparisons between men and women on the ambivalent attitudes scales appear in Table 1. As previously found in cross-national 
Table 1. Means, standard deviations, and gender differences in ambivalent sexism and attitudes toward men scores.

\begin{tabular}{lcccccc}
\hline & \multicolumn{2}{l}{ Male $(n=154)$} & & \multicolumn{2}{l}{ Female $(n=157)$} & \\
\cline { 2 - 3 } & $M$ & SD & & $M$ & SD & $t$ \\
\hline Hostile sexism (HS) & 2.96 & 1.09 & & 2.44 & 1.00 & $4.36^{* * *}$ \\
Benevolent sexism (BS) & 2.78 & 0.98 & & 2.97 & 1.05 & -1.61 \\
Hostility toward men (HM) & 2.55 & 0.86 & & 2.86 & 1.01 & $-2.89^{* *}$ \\
Benevolence toward men (BM) & 2.78 & 1.14 & & 2.62 & 1.12 & 1.25 \\
\hline
\end{tabular}

Note: Tests of significance were two-tailed.

$* p<0.05$.

$* * p<0.01$.

$* * * p<0.001$.

studies (Glick et al., 2000, 2004), there were gender differences in HM and women. Women $(M=2.86)$ scored significantly higher than did men $(M=2.55)$ on HM, $t(309)=2.89, p<0.01$. In contrast, men $(M=2.96)$ scored significantly higher than women $(M=2.44)$ on HS, $t(309)=4.36, p<0.001$. As in many other nations, the gender differences in BS and BM were much smaller and did not reach significance (cf. Glick et al., 2004).

\section{Ambivalent sexism and perceptions of a breadwinning/caregiving woman}

Hypothesis 1 suggested that HS would be associated with negative perceptions of the female breadwinner, whereas Hypothesis 2 suggested that BS would be associated with positive perceptions of the female caregiver. Following Glick and Fiske's recommendation (Glick \& Fiske, 1996, 1999), partial correlations were used to test the effects of HS while controlling for BS and vice versa.

Table 2 presents the results according to the target person's gender and role. As can be seen in the table, when male and female participants were pooled together, the findings supported the hypothesized relationships between HS and negative perceptions of the female breadwinner, and between BS and positive perceptions of the female caregiver. In line with the first hypothesis, hostile sexist participants attributed less warmth $(r=-0.42, p<0.001)$ and competence $(r=-0.30, p<0.01)$ to the breadwinning woman, and perceived her as experiencing fewer positive $(r=-0.58$, $p<0.001)$ and more negative emotions $(r=-0.46, p<0.001)$. As hypothesized, BS was generally unrelated to perceptions of the breadwinning woman, with the exception of greater attribution of positive emotions by benevolent sexists $(r=0.43, p<0.001)$. In addition, and in line with the second hypothesis, benevolent sexist participants attributed more warmth $(r=0.46, p<0.001)$ and competence $(r=0.45, p<0.001)$ to the caregiving woman, and perceived her as experiencing fewer negative emotions $(r=0.61, p<0.001)$. Their tendency to perceive her as experiencing more positive emotions was not significant.

Unexpected results emerged with regard to HS and perceptions of the caregiving woman. In contrast to the predictions derived from ambivalent sexism theory, hostile sexist participants tended to view the primary caregiving woman as less warm 
Table 2. Partial correlations of ASI and AMI scales with perceptions of caregiving and breadwinning male and female targets.

\begin{tabular}{|c|c|c|c|c|c|c|c|c|}
\hline & \multicolumn{4}{|c|}{ Female target } & \multicolumn{4}{|c|}{ Male target } \\
\hline & \multicolumn{2}{|c|}{ Caregiver } & \multicolumn{2}{|c|}{ Breadwinner } & \multicolumn{2}{|c|}{ Caregiver } & \multicolumn{2}{|c|}{ Breadwinner } \\
\hline & HS & $\mathrm{BS}$ & HS & $\mathrm{BS}$ & $\mathrm{HM}$ & $\mathrm{BM}$ & $\mathrm{HM}$ & $\mathrm{BM}$ \\
\hline \multicolumn{9}{|c|}{ All participants } \\
\hline Warmth $^{\mathrm{a}}$ & $-0.44^{* * *}$ & $0.46^{* * *}$ & $-0.42^{* * *}$ & 0.14 & $0.24^{*}$ & $-0.24^{*}$ & -0.20 & 0.11 \\
\hline Competence $^{a}$ & $-0.56^{* * *}$ & $0.45^{* * *}$ & $-0.30^{* *}$ & -0.01 & 0.18 & $-0.25^{*}$ & -0.21 & -0.05 \\
\hline $\begin{array}{l}\text { Positive } \\
\text { emotions }^{\mathrm{a}}\end{array}$ & -0.19 & 0.16 & $-0.58^{* * *}$ & $0.43^{* * *}$ & 0.20 & $-0.29^{* *}$ & 0.15 & -0.08 \\
\hline $\begin{array}{l}\text { Negative } \\
\text { emotions }^{\mathrm{b}}\end{array}$ & $-0.60^{* * *}$ & $0.61^{* * *}$ & $-0.46^{* * *}$ & 0.17 & $0.22^{*}$ & $-0.34^{* *}$ & -0.04 & -0.09 \\
\hline \multicolumn{9}{|c|}{ Male participants } \\
\hline Warmth $^{\mathrm{a}}$ & $-0.57^{* * *}$ & $0.42^{*}$ & $-0.61^{* * *}$ & -0.05 & $0.49^{* * *}$ & $-0.39^{*}$ & -0.07 & 0.04 \\
\hline Competence $^{\mathrm{a}}$ & $-0.63^{* * *}$ & $0.44^{* *}$ & -0.25 & 0.31 & 0.01 & -0.06 & $-0.42^{* *}$ & 0.01 \\
\hline $\begin{array}{l}\text { Positive } \\
\text { emotions }^{\mathrm{a}}\end{array}$ & -0.09 & 0.25 & $-0.50^{* * *}$ & $0.40^{*}$ & 0.19 & -0.24 & 0.14 & -0.09 \\
\hline $\begin{array}{l}\text { Negative } \\
\text { emotions }{ }^{\mathrm{b}}\end{array}$ & $-0.68^{* * *}$ & $0.73^{* * *}$ & $-0.73^{* * *}$ & 0.15 & 0.19 & $-0.41^{* *}$ & -0.25 & -0.12 \\
\hline \multicolumn{9}{|c|}{ Female participants } \\
\hline Warmth $^{\mathrm{a}}$ & -0.19 & 0.29 & $-0.35^{*}$ & 0.11 & 0.15 & -0.22 & $-0.41^{*}$ & 0.28 \\
\hline Competence $^{\mathrm{a}}$ & $-0.44^{* *}$ & 0.31 & -0.23 & -0.05 & $0.33^{*}$ & $-0.40^{* *}$ & -0.34 & 0.25 \\
\hline $\begin{array}{l}\text { Positive } \\
\text { emotions }^{\mathrm{a}}\end{array}$ & $-0.33^{*}$ & 0.10 & $-0.64^{* * *}$ & $0.48^{* *}$ & 0.22 & $-0.35^{*}$ & -0.01 & 0.12 \\
\hline $\begin{array}{l}\text { Negative } \\
\text { emotions }{ }^{b}\end{array}$ & $-0.53^{* * *}$ & $0.41^{* *}$ & -0.21 & $0.43^{* *}$ & 0.25 & -0.24 & -0.05 & 0.28 \\
\hline
\end{tabular}

Note: $\mathrm{HM}=$ hostility towards men; $\mathrm{BM}=$ benevolence towards men; $\mathrm{HS}=$ hostile sexism; $\mathrm{BS}=$ benevolent sexism. All correlations are partial correlations, controlling for the positive relationships between the HS and BS subscales, or the HM and BM subscales.

${ }^{a}$ Higher scores reflect greater attribution of trait/emotion.

${ }^{\mathrm{b}}$ Higher scores reflect lower attribution of emotion.

${ }^{*} p<0.05$.

$* * p<0.01$.

$* * * p<0.001$.

$(r=-0.44, p<0.001)$ and competent $(r=-0.56, p<0.001)$, and attributed more negative emotions to her $(r=-0.60, p<0.001)$.

Separate analyses for male and female participants yielded similar (although less consistent) patterns of results. As shown in Table 2, all of the hypothesized correlations were in the predicted direction, but some of them were weak and statistically insignificant. These inconsistencies may stem from the small sample sizes ( $n=34-40$ participants per condition).

\section{Ambivalence toward men and perceptions of a breadwinninglcaregiving man}

The third hypothesis suggested that HM would be associated with negative perceptions of the male breadwinner and positive perceptions of the male caregiver, and Hypothesis 4 predicted that BM would be associated with positive perceptions of 
the male breadwinner and negative perceptions of the male caregiver. Again, partial correlations were used to test the effects of hostility while controlling for benevolence and vice versa (Glick \& Fiske, 1996, 1999).

As can be seen in Table 2, when male and female participants were pooled together, the findings supported the fourth hypothesis regarding the relationships between BM and negative perceptions of the male caregiver. Participants who endorsed benevolent attitudes attributed less warmth $(r=-0.24, p<0.05)$ and competence $(r=-0.25$, $p<0.05)$ to the caregiving man, and perceived him as experiencing fewer positive $(r=-0.29, p<0.01)$ and more negative emotions $(r=-0.34, p<0.01)$. The findings regarding the association between $\mathrm{HM}$ and positive perceptions of the male caregiver were generally in line with the third hypothesis, although weaker and sometimes insignificant. Participants who endorsed hostile attitudes attributed more warmth $(r=0.24, p<0.05)$ and fewer negative emotions $(r=0.22, p<0.05)$ to the caregiving man, and their perceptions of competence and positive emotions were in the expected direction ( $r=0.18$ and 0.20 respectively, ns.).

The findings regarding the perceptions of the male breadwinner did not confirm the hypothesized relationships between HM and negative perceptions, or between $\mathrm{BM}$ and positive perceptions of that target. Some of the hypothesized associations were in the expected direction, but none of them reached statistical significance.

Finally, separate analyses for male and female participants yielded weaker and less consistent results. As can be seen in Table 2, the hypothesized correlations between ambivalent attitudes and perceptions of the male caregiver were in the predicted direction, but less than half of them were statistically significant. These inconsistencies presumably stem from the smaller sample sizes $(n=42-43$ participants per condition).

\section{Discussion}

The current study was designed to explore the influence of ambivalent gender attitudes on people's perceptions of men and women who violate traditional gender roles. Using hypothetical scenarios describing the daily life of an individual man or woman, the study sought to reduce the stereotypic nature of abstract category labels (e.g., 'homemakers,' 'career women') when exploring participants' perceptions. Drawing on ambivalent sexism theory, it was hypothesized that hostile sexists would exhibit more negative perceptions of a female breadwinner, whereas benevolent sexists would exhibit more positive perceptions of a female caregiver. It was also hypothesized that people who endorsed hostile attitudes toward men would react more negatively to a traditional male breadwinner and more positively to a nontraditional male caregiver. Finally, people who endorsed benevolent attitudes toward men were expected to react more positively to a male breadwinner and more negatively to a male caregiver.

The findings generally supported the hypotheses regarding perceptions of the female target. In line with Glick et al.'s findings with abstract category labels (Glick et al., 1997), HS was related to more negative perceptions of a woman who is a main breadwinner married to a primary caregiver, whereas BS was generally unrelated to participants' perceptions of such a woman. In addition, BS was related to more positive perceptions of a woman who is a primary caregiver married to a breadwinning husband. These findings show that the implications of sexist attitudes are 
not limited to judgments of generalized social categories. Rather, they attest to the importance of sexist attitudes in determining perceptions of an individualized target whose portrayal provides rich information about family circumstances and routine daily life.

Unexpected findings emerged with regard to HS and perceptions of a primary caregiving woman. In contrast to the predictions derived from ambivalent sexism theory, HS was not restricted to the nontraditional career woman. Rather, it was also related to more negative perceptions of the relatively traditional woman, who is married to a primary breadwinning husband. Thus, a woman described as returning from work at noon and bearing sole responsibility for housework and childcare elicited both positive responses from benevolent sexists and negative responses from hostile sexists.

These findings are inconsistent with Glick et al.'s findings with the 'homemaker' category label, and may stem from describing the traditional woman in this study as combining (limited) paid work with childcare. This scenario was chosen for the study because it best reflects the Jewish Israeli participants' social context, in which the vast majority of mothers are in the labor force, and the complete 'homemaker' category is marginal (Central Bureau of Statistics, 2009). However, it is possible that this relatively complex portrayal left some room for subjective construal. That is, benevolent sexist participants may have categorized this female target as a traditional woman because of her caregiving responsibilities, while hostile sexist participants may have categorized her as a nontraditional woman because of her part-time job. Further research is needed to explore such nuances and examine how sexist attitudes affect the perceptions of women who are located on various points along the housewife-career woman continuum.

The associations between ambivalence toward men and participants' perceptions of a primary caregiving man were generally in line with the hypotheses. BM was consistently related to negative views of a nontraditional man who returns from work at noon and takes care of his children while his wife is at work. These findings are consistent with Sakalli-Ugurlu's study (2010) in which BM predicted negative perceptions of men who study social sciences. The current findings are particularly important in demonstrating the restrictive implications of BM. They confirm Glick and Fiske's $(1996,1999,2001)$ argument that benevolence - despite its positive tone is prescriptive in its nature and therefore also restrictive and eventually negative.

$\mathrm{HM}$, on the other hand, was (although more weakly) related to positive views of the primary caregiving man. That is, participants who endorsed more hostile attitudes toward men perceived the nontraditional primary caregiver more favorably. This is in line with the hypotheses and with Glick and Fiske's (1999) notion of hostility as an expression of resentment toward the patriarchal social order. Glick and Fiske (2001) also argued, however, that HM is not a form of feminist consciousness, as evidenced by its positive correlations with the other three subscales and with national indicators of gender inequality. Nevertheless, the current findings suggest that such hostility carries a somewhat subversive tone, which makes it qualitatively different than the other three ambivalent attitude sub-scales. While the other ambivalence sub-scales were related to perceptions that justify traditional gender roles (i.e., negative perceptions of a nontraditional woman (HS) and man (BM), or positive perceptions of a traditional woman (BS)), HM was related to perceptions that support social change (i.e., positive perceptions of a nontraditional 
man). To more fully understand the nature of HM and its implications for gender attitudes, more research within diverse social domains is needed. It would be interesting, for example, to examine the associations between hostility and perceptions of other gender norm violators such as gay men or men in feminine professions.

Finally, the findings did not support the hypotheses regarding the associations between ambivalent attitudes toward men and perceptions of the traditional male breadwinner. A plausible explanation for the absence of correlations follows from the prevalence of this normative target. Whereas there is a large diversity in women's arrangements of paid work and childcare, being a main breadwinner is a normative default for men. As attribution theories pointed out decades ago (Jones \& Davis, 1965; Kelley, 1967), normative socially desirable behaviors seem less indicative of a person's characteristics, and therefore result in attenuated trait attributions. Counternormative behaviors, on the other hand (e.g., being a primary caregiving man), attract considerable attention and seem more informative and therefore as justifying stronger and more confident inferences about the person's traits and emotions (see also deviance regulation theory, Blanton \& Christie, 2003). It is therefore likely that the participants in the two female conditions and in the nontraditional male condition engaged in more intensive attributional processes (guided by their gender beliefs), than did participants in the traditional male condition.

Although this study makes an important contribution to understanding the implications of ambivalent gender attitudes, it is limited by its use of a sample of highly educated Jewish Israelis in their twenties. Given the cultural embeddedness of gender attitudes and their associations with age and education (Glick, Lameiras, \& Castro, 2002), the generalizability of the results to other populations is curtailed. In addition, the relatively small sample size did not allow a systematic examination of gender differences in perceptions of traditional and nontraditional targets. Replicating this study in other cultures and with larger samples would address these limitations and strengthen the conclusions drawn from the current findings.

In addition, the correlational design of this study limits the conclusions that can be drawn regarding the causal links between ambivalent sexism and perceptions of normative and norm-violating individuals. It is possible to argue, for example, that negative attitudes toward individuals who deviate from gender norms cause people to adopt more hostile gender attitudes. Nevertheless, given the broad and general nature of sexist attitudes, it seems unlikely that negative perceptions of norm violators are the cause rather than the consequence of these attitudes. Future studies that manipulate the salience of hostile and benevolent attitudes may be able to establish the assumed causality from sexism to perceptions of individual targets with greater confidence.

Taken together, the findings confirmed predictions derived from ambivalent sexism theory regarding the role of benevolent and HS in perceptions of an individualized woman in a traditional or nontraditional role. Consistent with previous studies (e.g., Lee et al., 2010), these findings show that benevolence and hostility toward women work together to promote the gender status quo. More intriguing findings, however, were found as regards the perceptions of male targets. Whereas ambivalent attitudes toward men were not related to perceptions of the normative breadwinning man, their relationships with perceptions of the primary caregiving man raise two important theoretical issues that deserve further investigation: the prescriptive nature of $\mathrm{BM}$ was reflected in benevolent participants' tendency to perceive the norm-violating man more negatively; and the subversive nature of 


\section{R. Gaunt}

HM was reflected in hostile participants' tendency to exhibit more favorable perceptions of the counter-normative caregiving man. Future research should investigate the nature of benevolence and HM and their implications for various domain-specific attitudes and behaviors. Such an extension of the present work would deepen our understanding of ambivalent gender attitudes and their operation.

\section{Notes on contributor}

Dr. Ruth Gaunt is a Reader in the School of Psychology at the University of Lincoln. Her research interests include the social psychology of gender, parenting in diverse family forms and the determinants of parental involvement in childcare.

\section{References}

Abrams, D., Viki, G. T., Masser, B., \& Bohner, G. (2003). Perceptions of stranger and acquaintance rape: The role of benevolent and hostile sexism in victim blame and rape proclivity. Journal of Personality and Social Psychology, 84(1), 111-125. doi:10.1037/00223514.84.1.111

Becker, J. C. (2010). Why do women endorse hostile and benevolent sexism? The role of salient female subtypes and internalization of sexist contents. Sex Roles, 62(7-8), 453-467. doi:10.1007/s11199-009-9707-4

Blanton, H., \& Christie, C. (2003). Deviance regulation: A theory of action and identity. Review of General Psychology, 7(2), 115-149. doi:10.1037/1089-2680.7.2.115

Brescoll, V. L., \& Uhlmann, E. L. (2005). Attitudes toward traditional and nontraditional parents. Psychology of Women Quarterly, 29(4), 436-445. doi:10.1111/j.1471-6402.2005. 00244.x

Bridges, J. S., Etaugh, C., \& Barnes-Farrell, J. (2002). Trait judgments of stay-at-home and employed parents: A function of social role and/or shifting standards? Psychology of Women Quarterly, 26(2), 140-150. doi:10.1111/1471-6402.00052

Bulanda, R. E. (2004). Paternal involvement with children: The influence of gender ideologies. Journal of Marriage and Family, 66(1), 40-45. doi:10.1111/j.0022-2455.2004.00003.x

Central Bureau of Statistics. (2009). Labour force surveys - Special Publication 1417. Jerusalem: CBS.

Charles, M., \& Cech, E. (2010). Beliefs about maternal employment. In J. Treas \& S. Drobnič (Eds.), Dividing the domestic: Men, women, and household work in cross-national perspective (pp. 147-174). Palo Alto, CA: Stanford University Press.

Chen, Z., Fiske, S. T., \& Lee, T. L. (2009). Ambivalent sexism and power-related gender-role ideology in marriage. Sex Roles, 60(11-12), 765-778. doi:10.1007/s11199-009-9585-9

Coleman, J. M., \& Franiuk, R. (2011). Perceptions of mothers and fathers who take temporary work leave. Sex Roles, 64(5-6), 311-323. doi:10.1007/s11199-010-9918-8

Cuddy, A. J. C., Fiske, S. T., \& Glick, P. (2008). Warmth and competence as universal dimensions of social perception: The Stereotype Content Model and the BIAS Map. Advances in Experimental Social Psychology, 40, 61-149. doi:10.1016/S0065-2601(07)00002-0

Eastwick, P. W., Eagly, A. H., Glick, P., Johannesen-Schmidt, M. C., Fiske, S. T., Blum, A. M., ... Volpato, C. (2006). Is traditional gender ideology associated with sex-typed mate preferences? A test in nine nations. Sex Roles, 54(9-10), 603-614. doi:10.1007/s11199-0069027-x

Etaugh, C., \& Folger, D. (1998). Perceptions of parents whose work and parenting behaviors deviate from role expectations. Sex Roles, 39(3/4), 215-223. doi:10.1023/A:10188504 04838

Fiske, S. T., Cuddy, A. J. C. P., \& Glick, P. (2007). Universal dimensions of social cognition: Warmth and competence. Trends in Cognitive Sciences, 11(2), 77-83. doi:10.1016/ j.tics.2006.11.005 
Fiske, S. T., Cuddy, A. J. P. C., Glick, P., \& Xu, J. (2002). A model of (often mixed) stereotype content: Competence and warmth respectively follow from perceived status and competition. Journal of Personality and Social Psychology, 82(6), 878-902. doi:10.1037/ 0022-3514.82.6.878

Forbes, G. B., Adams-Curtis, L. E., Hamm, N. R., \& White, K. B. (2003). Perceptions of the woman who breastfeeds: The role of erotophobia, sexism, and attitudinal variables. Sex Roles, 49(7/8), 379-388. doi:10.1023/A:1025116305434

Forbes, G. B., Collinsworth, L. L., Jobe, R. L., Braun, K. D., \& Wise, L. M. (2007). Sexism, hostility toward women, and endorsement of beauty ideals and practices: Are beauty ideals associated with oppressive beliefs? Sex Roles, 56(5-6), 265-273. doi:10.1007/s11199-0069161-5

Fowers, A. F., \& Fowers, B. J. (2010). Social dominance and sexual self-schema as moderators of sexist reactions to female subtypes. Sex Roles, 62(7-8), 468-480. doi:10.1007/s11199-0099607-7

Gaunt, R. (2006). Biological essentialism, gender ideologies, and role attitudes: What determines parents' involvement in child care. Sex Roles, 55(7-8), 523-533. doi:10.1007/ s11199-006-9105-0

Gershuny, J. (2004). Time, through the life course, in the family. In J. Scott, J. Treas, \& M. Richards (Eds.), The Blackwell companion to the sociology of families (pp. 158-173). Malden, MA: Blackwell Publishing Ltd.

Gill, M. J. (2003). Biased against "them" more than "him": Stereotype use in group-directed and individual-directed judgments. Social Cognition, 21(5), 321-348. doi:10.1521/ soco.21.5.321.28684

Glick, P., Diebold, J., Bailey-Werner, B., \& Zhu, L. (1997). The two faces of Adam: Ambivalent sexism and polarized attitudes toward women. Personality and Social Psychology Bulletin, 23(12), 1323-1334. doi:10.1177/01461672972312009

Glick, P., \& Fiske, S. T. (1996). The Ambivalent Sexism Inventory: Differentiating hostile and benevolent sexism. Journal of Personality and Social Psychology, 70(3), 491-512. doi:10.1037/0022-3514.70.3.491

Glick, P., \& Fiske, S. T. (1997). Hostile and benevolent sexism: Measuring ambivalent sexist attitudes toward women. Psychology of Women Quarterly, 21(1), 119-135. doi:10.1111/ j.1471-6402.1997.tb00104.x

Glick, P., \& Fiske, S. T. (1999). The ambivalence toward men inventory: Differentiating hostile and benevolent beliefs about men. Psychology of Women Quarterly, 23(3), 519-536. doi:10.1111/j.1471-6402.1999.tb00379.x

Glick, P., \& Fiske, S. T. (2001). Ambivalent sexism. Advances in Experimental Social Psychology, 33, 115-188.

Glick, P., Fiske, S. T., Mladinic, A., Saiz, J. L., Abrams, D., Masser, B., ... Lopez, W. (2000). Beyond prejudice as simple antipathy: Hostile and benevolent sexism across cultures. Journal of Personality and Social Psychology, 79(5), 763-775. doi:10.1037/00223514.79.5.763

Glick, P., Lameiras, M., \& Castro, Y. R. (2002). Education and Catholic religiosity as predictors of hostile and benevolent sexism toward women and men. Sex Roles, 47(9/10), 433-441. doi:10.1023/A:1021696209949

Glick, P., Lameiras, M., Fiske, S. T., Eckes, T., Masser, B., Volpato, C., ... Glick, P. (2004). Bad but bold: Ambivalent attitudes toward men predict gender inequality in 16 nations. Journal of Personality and Social Psychology, 86(5), 713-728. doi:10.1037/00223514.86.5.713

Glick, P., Sakalli-Ugurlu, N., Ferreira, M. C., \& De Souza, M. A. (2002). Ambivalent sexism and attitudes toward wife abuse in Turkey and Brazil. Psychology of Women Quarterly, 26(4), 292-297. doi:10.1111/1471-6402.t01-1-00068

Greenstein, T. N. (1996). Husbands' participation in domestic labor: Interactive effects of wives' and husbands' gender ideologies. Journal of Marriage and the Family, 58(3), 585-595. doi: $10.2307 / 353719$

Jones, E. E., \& Davis, K. E. (1965). A theory of correspondent inferences: From acts to dispositions. In L. Berkowitz (Ed.), Advances in experimental social psychology (Vol. 2, pp. 219-266). New York: Academic Press. 


\section{$16 \quad$ R. Gaunt}

Kelley, H. H. (1967). Attribution theory in social psychology. In D. Levine (Ed.), Nebraska Symposium on Motivation (Vol. 15, pp. 129-238). Lincoln: University of Nebraska Press.

Knudsen, K., \& Waerness, K. (2008). National context and spouses' housework in 34 countries. European Sociological Review, 24(1), 97-113. doi:10.1093/esr/jcm037

Lachance-Grzela, M., \& Bouchard, G. (2010). Why do women do the lion's share of housework? A decade of research. Sex Roles, 63, 767-780. doi:10.1007/s11199-010-9797-z

Lavee, Y., \& Katz, R. (2003). The family in Israel: Between tradition and modernity. Marriage and Family Review, 35(1-2), 193-217. doi:10.1300/J002v35n01_11

Lee, T. L., Fiske, S. T., Glick, P., \& Chen, Z. (2010). Ambivalent sexism in close relationships: (Hostile) power and (benevolent) romance shape relationship ideals. Sex Roles, 62(7-8), 583-601. doi:10.1007/s11199-010-9770-x

Park, B., Smith, J. A., \& Correll, J. (2008). "Having it all" or "doing it all"? Perceived trait attributes and behavioral obligations as a function of workload, parenthood, and gender. European Journal of Social Psychology, 38(7), 1156-1164. doi:10.1002/ejsp.535

Sakalli-Ugurlu, N. (2010). Ambivalent sexism, gender, and major as predictors of Turkish college students' attitudes toward women and men's atypical educational choices. Sex Roles, 62(7-8), 427-437. doi:10.1007/s11199-009-9673-x

Scott, J., Dex, S., \& Joshi, H. (Eds.). (2008). Women and employment: Changing lives and new challenges. Cheltenham: Edward Elgar.

Travaglia, L. K., Overall, N. C., \& Sibley, C. G. (2009). Benevolent and hostile sexism and preferences for romantic partners. Personality and Individual Differences, 47(6), 599-604. doi:10.1016/j.paid.2009.05.015 